\title{
Ground-Based Corroboration of GOES-17 Fire Detection Capabilities During Ignition of the Kincade Fire
}

\author{
T. TODD LINDLEY AND ALEXANDER B. ZWINK \\ NOAA/National Weather Service, Norman, OK \\ CHAD M. GRAVELLE \\ NOAA/National Weather Service, Southern Region Headquarters, Fort Worth, TX \\ CHRISTOPHER C. SCHMIDT \\ Cooperative Institute for Meteorological Satellite Studies, University of Wisconsin, Madison, WI \\ CYNTHIA K. PALMER AND SCOTT T. ROWE \\ NOAA/National Weather Service, Monterey, CA \\ ROBYN HEFFERNAN \\ NOAA/National Weather Service, Boise, ID \\ NEAL DRISCOLL \\ University of California, San Diego, CA \\ GRAHAM M. KENT \\ University of Nevada, Reno, $N V$
}

(Manuscript received 24 March 2020; review completed 27 July 2020)

\begin{abstract}
Corroboration of Geostationary Operational Environmental Satellite-17 (GOES-17) wildland fire detection capabilities occurred during the 24 October 2019 (evening of 23 October LST) ignition of the Kincade Fire in northern California. Post-analysis of remote sensing data compared to observations by the ALERTWildfire fire surveillance video system suggests that the emerging Kincade Fire hotspot was visually evident in GOES17 shortwave infrared imagery $52 \mathrm{~s}$ after the initial near-infrared heat source detected by the ground-based camera network. GOES-17 Advanced Baseline Imager Fire Detection Characteristic algorithms registered the fire $5 \mathrm{~min}$ after ignition. These observations represent the first documented comparative dataset between fire initiation and satellite detection, and thus provide context for GOES-16/17 wildland fire detections.
\end{abstract}

\section{Introduction}

The Advanced Baseline Imager's (ABI) improved radiometric, spectral, spatial, and temporal resolution on board the Geostationary Operational Environmental Satellite (GOES)-R series of weather satellites (GOES16, GOES-17, and upcoming GOES-T and GOES-U) are recognized as revolutionary tools for the provision of impact-based decision support services (IDSS) in wildland fire incidents (Lindley et al. 2016, 2019).
The unprecedented temporal and improved spatial resolution has provided early detection and first alerting of potentially significant wildfire occurrences for firefighting officials (Uccellini and Ten Hoeve 2019), but the utility of satellite-based fire detection and monitoring in support of the wildland fire community is not a consistent practice of the National Weather Service (NWS) or other federal fire agencies. Preliminary efforts to leverage this technology in the operational environment, however, are credited with

Corresponding author address: T. Todd Lindley, 120 David L. Boren Blvd., Norman, OK 73072 
saving lives and property (NOAA 2018). Although numerous anecdotal accounts of successful fireweather IDSS have been provided by NWS and fire/ emergency management personnel utilizing GOES$16 / 17$, verifiable data on fire detections relative to the observed ignition of fire on the ground has not been previously documented. While only one example, this analysis provides important novel ground truth verification that demonstrates effectiveness and utility of the GOES-16/17 ABI in both human-interpreted and algorithm-based wildland fire detection.

\section{Data and analysis}

Due to the shortwave infrared (SWIR) channel's sensitivity to subpixel heat, previous research has shown that the most useful channel for early detection of wildland fires on the GOES-R series ABI is channel 7, centered near $3.9 \mu \mathrm{m}$ (e.g., Dozier 1981, Weaver et al. 1995, Weaver et al. 2004). One of the significant improvements of the GOES-R series ABI is the increase in radiometric resolution. Specifically, the bits per pixel of the 3.9- $\mu \mathrm{m}$ channel has increased from 10 to 14 when compared to the legacy GOES imager (Schmit et al. 2017). Additionally, the maximum saturation temperature for the 3.9- $\mu \mathrm{m}$ channel increased from 337 $\mathrm{K}$ to greater than $400 \mathrm{~K}$, which in turn allows the GOES$16 / 17$ to sense more heat and permits stakeholders to monitor wildland fires in more detail. The increase in spectral capabilities on the ABI, that includes the 2.2$\mu \mathrm{m}$ and 1.6- $\mu \mathrm{m}$ near-IR channels, is also important for monitoring wildland fires. As the sub-pixel temperature anomaly increases, the peak of the Planck Function shifts toward these shorter wavelengths (Weaver et al. 2004 and Schmidt 2020). Therefore, the 2.2- $\mu \mathrm{m}$ and $1.6-\mu \mathrm{m}$ channels help supplement information from the 3.9- $\mu \mathrm{m}$ channel. These additional near-IR channels assist in identifying and determining the intensity of wildland fires and are combined with the $3.9-\mu \mathrm{m}$ channel to create false color red-green-blue composite images (Elmer et al. 2016 and Fuell et al. 2016), which are frequently used as decision aids in operations (e.g., Elsenheimer and Gravelle 2019; CIRA 2020). The increase in spatial resolution of the $3.9-\mu \mathrm{m}$ channel, from $4 \mathrm{~km}$ to $2 \mathrm{~km}$, also positively impacts wildland fire detection. A given fire now occupies a $4 x$ larger fraction of the pixel footprint, leading to higher visual contrast and notable increase in brightness temperatures. NWS forecasters have used GOES-16/17 to detect point heat sources such as oil rig burnoffs, burning structures with subtle heat signatures as low as $1 \mathrm{~K}$ above background brightness temperature, and wildland fire on the order of acres (Schmidt 2020). These examples illustrate how minute-by-minute monitoring of GOES-16/17's high radiometric, spectral, and spatial resolution imagery, with $5 x$ improved temporal resolution over legacy GOES, when interpreted by skilled practitioners in context of the ambient environment, allows for the identification of subtle fire signatures, and thus revolutionizes remotely sensed wildland fire detection capabilities.

The Fire Detection and Characterization (FDC) algorithm is the National Oceanic and Atmospheric Administration's (NOAA) operational fire algorithm. FDC data is produced by NOAA for the 5-min CONtiguous United States (CONUS) and 10-min FD (Full Disk) scans. The algorithm provides a metadata mask that identifies pixels which are considered to be fire signatures and assigns a fire likelihood category. For most suspected fire signals, the algorithm provides Fire Radiative Power (FRP) and for a subset of higher confidence fire detections, estimated Fire Temperature (FT) and Fire Area (FA) are provided. FT and FA are calculated using simultaneous equations and are dependent on one another. They represent a hypothetical heat source that would match the observed temperatures. Due to radiometric error, diffraction, and remapping of $\mathrm{ABI}$ data, the solutions are imprecise and primarily intended to be used in numerical models for aerosols and smoke. Therefore, FT and FA should not be taken as literal values representing the temperature and areal extent of wildland fire. The FRP, FT, and FA products are available in the NWS's Advanced Weather Interactive Processing System (AWIPS), but the metadata mask is not. Operational availability of FDC data in AWIPS is $\sim 3$ min latency compared to $\sim 25$ s latency for raw base ABI data such as 1-min MDS (Mesoscale Domain Sector) SWIR.

The Kincade Fire burned $315 \mathrm{~km}^{2}(77,758 \mathrm{ac})$, destroyed 374 structures, and injured four people in Sonoma County, California, between 24 October and 6 November 2019 (Cal Fire, cited 2019). At the time of ignition, GOES-17's SWIR 3.9- $\mu \mathrm{m}$ channel data was available in AWIPS from FD scans every 10 min, from CONUS scans every $5 \mathrm{~min}$, and from MDS scans every 1 min. ALERTWildfire, a near-infrared video system specifically designed for monitoring wildland fires, provided novel ground-based corroboration of GOES17 fire detection capabilities during the ignition and initial spread of the Kincade Fire in northern California 
on 24 October 2019 (evening of 23 October LST). The Barham North ALERTWildfire near-IR camera $(38.51 \mathrm{~N} ; 122.66 \mathrm{~W})$ fortuitously observed the fire's ignition during downslope windstorm conditions from a line-of-site vantage point $32 \mathrm{~km}$ south-southeast of its origin $(38.78 \mathrm{~N} 122.78 \mathrm{~W}$, approximated by GOES17). Summary comparisons of the ALERTWildfire and operationally available GOES-17 depictions of the Kincade Fire ignition timeline are shown in graphical and table form (Fig. 1 and Table 1).

ALERTWildfire recorded the extinction of an artificial light source, likely resulting from an electrical disruption, in visual proximity to the eventual Kincade Fire ignition at 04:19:54 UTC (hh:mm:ss, format applies to all time references hereafter). This was followed by the initial emergence of a near-IR heat signature that can be seen in the ALERTWildfire imagery at 04:20:09 UTC with subsequent intensification thereafter. GOES17 SWIR data at 04:19:57 UTC showed no evidence of a wildland fire as an ambient SWIR brightness temperature of $17.4^{\circ} \mathrm{C}$ was present. However, the next available images at 04:21:01 UTC, approximately $52 \mathrm{~s}$ after the first near-IR glow was captured by the ALERTWildfire camera, and 04:21:57 UTC visually indicated brightening pixels with SWIR brightness temperatures of $19.8^{\circ} \mathrm{C}$ and $20.0^{\circ} \mathrm{C}$ respectively. By 04:22:57 and 04:23:57 UTC SWIR brightness temperatures increased to $25.5^{\circ} \mathrm{C}$ and $24.9^{\circ} \mathrm{C}$ respectively, and subsequent brightening to $59.8^{\circ} \mathrm{C}$ was observed by the end of the analysis at 04:36:57 UTC.

The operational FDC algorithm first detected the Kincade Fire at 04:26:57 UTC, 5 min after its initial visual identification in GOES-17 MDS SWIR data, with the FRP product sampling 78.5 MW. Ten minutes later, at 04:36:57 UTC, the operational FDC FT and FA products first detected the fire and were measured at $2975.2 \mathrm{~K}$ and $269 \mathrm{~m}^{2}$ respectively. At that time, the FRP product increased by a factor of more than three at 275.6 MW. As previously stated, the FT and FA products are only produced for high confidence fires while the FRP product is produced for low confidence fire detections. In this case, a preliminary representative interpretation of the FDC algorithm depiction of the Kincade Fire, considering the limitations of FT and FA data, would be "small and hot". It is noteworthy that SWIR brightness temperatures increased to greater than $100^{\circ} \mathrm{C}$ less than $1 \mathrm{~h}$ after the presented analysis. Similar GOES-16 SWIR brightness temperatures have been observed in association with extreme fire behavior (Lindley et al. 2019).

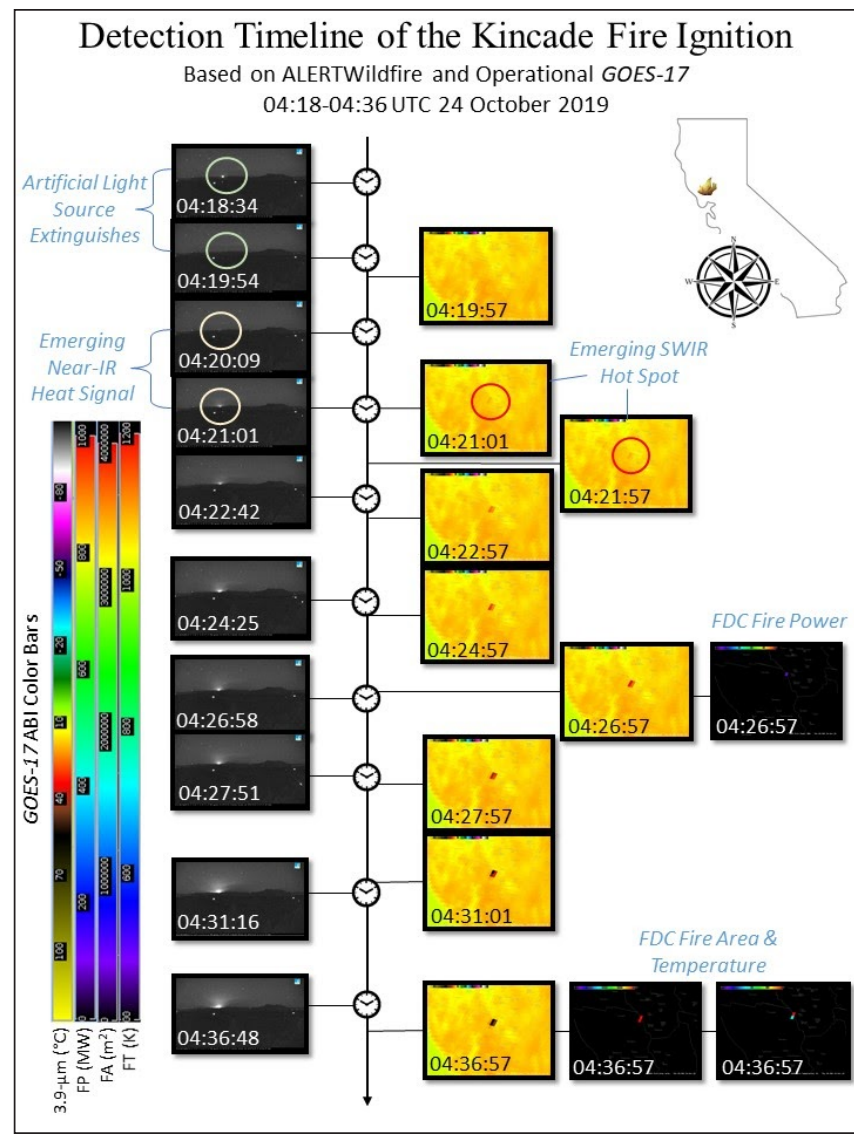

Figure 1. Graphical timeline comparison of ALERTWildfire and operational GOES-17 detections of the 24 October 2019 Kincade Fire ignition. Click image for an external version; this applies to all figures and hereafter.

\section{Discussion}

Comparative analysis of satellite and terrestrial intelligence shows that GOES-17 ABI detected evidence of the Kincade Fire ignition within $52 \mathrm{~s}$ of the first ground-based near-IR glow observed by the ALERTWildfire surveillance network. Initial satellite detection of the ignition was identified per human/ visual recognition of a SWIR hotspot. The operational FDC algorithm began to provide data on the fire $5 \mathrm{~min}$ later. This is an important finding as corroboration of the GOES-16/17 ABI fire detection capability is essential to establishing context for its utility as an early detection resource. Sensitivity of the GOES16/17 ABI fire detection capability varies with fire environment and resultant burn intensity. Hotspot signatures appear subtle, or may not be evident at all, in marginal or less critical fire environments, while hotter burn temperatures quickly saturate ABI pixels in high 
Table 1. Characteristics of fire detection via critical timestamps of ALERTWildfire (Barham North site) video and operationally available GOES-17 data for the Kincade Fire between 04:18:34 and 04:36:57 UTC 24 October 2019. Visual near-IR glow and visual hotspot indicate human identified signatures. FDC Fire Radiative Power (FRP), Fire Temperature (FT), and Fire Area (FA) reported from the 5-min CONUS sector scan data. Data update indicates data source which updated at the indicated time step, AW=ALERTWildfire, $\mathrm{CH} 7=G O E S-173.9 \mu \mathrm{m}$ SWIR, FDC $=$ GOES-17 ABI Fire Detection Characteristics algorithm.

\begin{tabular}{|c|c|c|c|c|c|c|c|}
\hline \multirow{3}{*}{$\begin{array}{c}\text { Time } \\
\text { (hh:mm:ss } \\
\text { UTC) }\end{array}$} & \multicolumn{7}{|c|}{ ALERTWildfire (Barham North) vs. GOES-17 - Kincade Fire 24 October 2019} \\
\hline & $\begin{array}{l}\text { ALERT } \\
\text { Wildfire }\end{array}$ & \multicolumn{6}{|c|}{ Operationally Available GOES-17 Data } \\
\hline & $\begin{array}{c}\text { Visual } \\
\text { near-IR } \\
\text { glow }\end{array}$ & $\begin{array}{l}\text { Visual } \\
\text { hotspot }\end{array}$ & $\begin{array}{c}\text { SWIR } \\
\text { brightness } \\
\mathrm{T}\left({ }^{\circ} \mathrm{C}\right)\end{array}$ & FRP (MW) & FT (K) & $\mathbf{F A}\left(\mathbf{m}^{2}\right)$ & Data Update \\
\hline 04:18:34 & $\mathrm{N}$ & $\mathrm{N}$ & 17.4 & -- & -- & -- & AW \\
\hline 04:19:54 & $\mathrm{N}$ & $\mathrm{N}$ & 17.4 & -- & -- & -- & AW \\
\hline 04:19:57 & $\mathrm{N}$ & $\mathrm{N}$ & 17.4 & -- & -- & -- & CH7 \\
\hline 04:20:09 & Y & $\mathrm{N}$ & 17.4 & -- & -- & -- & AW \\
\hline 04:21:01 & Y & Y & 19.8 & -- & -- & -- & CH7 \\
\hline 04:21:19 & $\mathrm{Y}$ & $\mathrm{Y}$ & 19.8 & -- & -- & -- & FDC \\
\hline $04: 21: 57$ & Y & Y & 20.0 & -- & -- & -- & CH7 \\
\hline 04:22:57 & $\mathrm{Y}$ & $\mathrm{Y}$ & 25.5 & -- & -- & -- & $\mathrm{CH} 7$ \\
\hline $04: 23: 57$ & Y & $\mathrm{Y}$ & 24.9 & -- & -- & -- & CH7 \\
\hline 04:24:57 & $\mathrm{Y}$ & $\mathrm{Y}$ & 30.5 & -- & -- & -- & CH7 \\
\hline 04:25:57 & $\mathrm{Y}$ & $\mathrm{Y}$ & 28.6 & -- & -- & -- & CH7 \\
\hline 04:26:19 & $\mathrm{Y}$ & $\mathrm{Y}$ & 28.6 & 78.5 & -- & -- & FDC \\
\hline 04:26:57 & $\mathrm{Y}$ & $\mathrm{Y}$ & 35.8 & 78.5 & -- & -- & $\mathrm{CH} 7$ \\
\hline 04:27:57 & $\mathrm{Y}$ & $\mathrm{Y}$ & 42.9 & 78.5 & -- & -- & CH7 \\
\hline 04:28:57 & $\mathrm{Y}$ & $\mathrm{Y}$ & 42.9 & 78.5 & -- & -- & CH7 \\
\hline 04:29:57 & $\mathrm{Y}$ & $\mathrm{Y}$ & 40.3 & 78.5 & -- & -- & CH7 \\
\hline 04:31:01 & $\mathrm{Y}$ & $\mathrm{Y}$ & 46.3 & 78.5 & -- & -- & CH7 \\
\hline 04:31:19 & $\mathrm{Y}$ & $\mathrm{Y}$ & 46.3 & 221.5 & -- & -- & FDC \\
\hline $0431: 57$ & $\mathrm{Y}$ & $\mathrm{Y}$ & 54.4 & 221.5 & -- & -- & CH7 \\
\hline $04: 32: 57$ & Y & Y & 59.3 & 221.5 & -- & -- & CH7 \\
\hline 04:33:57 & $\mathrm{Y}$ & $\mathrm{Y}$ & 51.7 & 221.5 & -- & -- & CH7 \\
\hline 04:34:57 & $\mathrm{Y}$ & $Y$ & 52.6 & 221.5 & -- & -- & CH7 \\
\hline 04:35:57 & $\mathrm{Y}$ & $\mathrm{Y}$ & 54.2 & 221.5 & -- & -- & CH7 \\
\hline 04:36:19 & $\mathrm{Y}$ & $\mathrm{Y}$ & 54.2 & 275.6 & 2975.2 & 269 & FDC \\
\hline 04:36:57 & $\mathrm{Y}$ & $\mathrm{Y}$ & 59.8 & 275.6 & 2975.2 & 269 & CH7 \\
\hline
\end{tabular}

end and more critical fire environments (Pletsch et al. 2019).

While the operational FDC data, which is only generated with 5-min CONUS-scale imagery, responded to the fire, the algorithm's detection lagged fire identification by manual interpretation of raw 1-min resolution ABI imagery. Due to this time lag between the identification of wildland fire in raw 3.9$\mu \mathrm{m}$ ABI imagery and detection by the operational FDC algorithm, the authors believe that there are significant limitations of the current FDC algorithm for use in the operational environment. In order to demonstrate potential future algorithm improvements, the FDC products processed using GOES-17 1-min MDS data at the University of Wisconsin-Madison's Space Science and Engineering Center (SSEC) were examined alongside the ALERTWildfire video (Fig. 2). In these data (not available in real-time operations), the FDC 


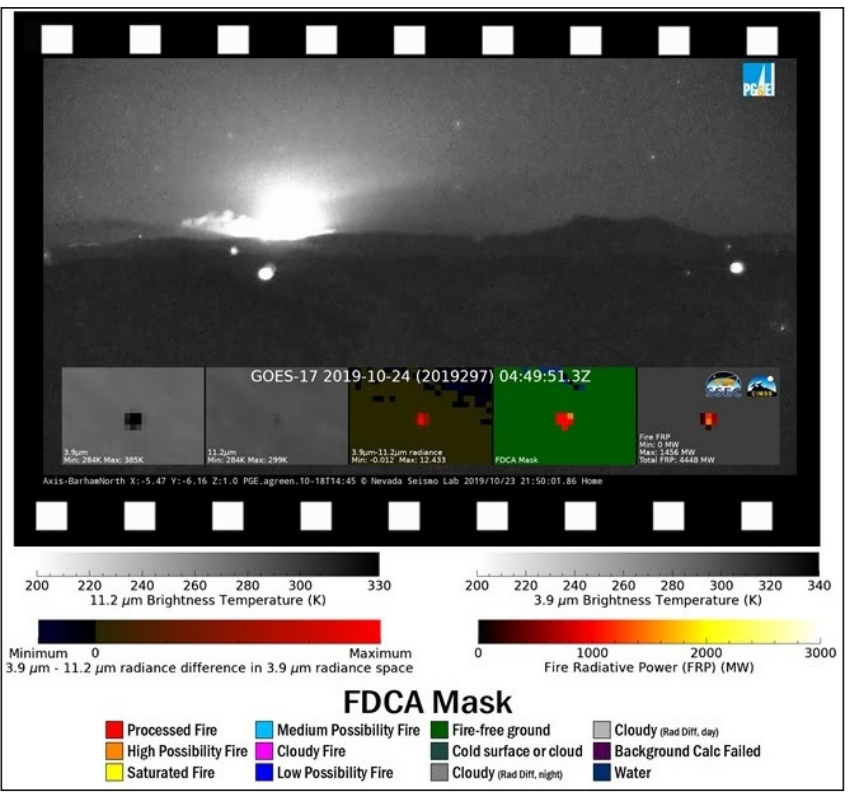

Figure 2. Video clip of the Kincade Fire ignition from the Barham North ALERTWildfire near-IR camera with corresponding GOES-17 $3.9 \mu \mathrm{m}, 11.2 \mu \mathrm{m}, 3.9 \mu \mathrm{m}-11.2$ $\mu \mathrm{m}$ radiance, Fire Detection Characteristics Algorithm (FDCA) Mask, and Fire Radiative Power (FRP) from 04:00:58-04:59:58 UTC 24 October 2019 (21:00:5821:59:58 PDT 23 October 2019). The FDC data resolution shown is 1-min, was produced by SSEC, and not operationally available in real-time. Click image for video $(59 \mathrm{~s}, 75 \mathrm{MB})$.

algorithm detected the Kincade Fire 2 min earlier than the operational FDC, at 04:24:57 UTC. Prior to the time of both operational and SSEC-processed algorithmbased detections, the Kincade Fire was already visually discernible when examining the radiance difference, in 3.9- $\mu \mathrm{m}$ radiance space, between raw GOES-17 $3.9-\mu \mathrm{m}$ and $11.2-\mu \mathrm{m}$ imagery. Thus, this case review suggests that manual monitoring of raw GOES-16/17 ABI data in conjunction with image differences provides opportunities for earlier notification of wildland fire ignition when compared to those provided by current automation processes. While the current automated FDC algorithm is generally a slower and less comprehensive means of identifying wildland fire versus visual inspection of raw ABI data, this analysis shows that improvements are within reach, and that automated detection can provide alerts to stakeholders in cases where manual monitoring is less intensive.

The Kincade Fire ignited within a critical fire weather environment (1700 UTC 23 October 2019 SPC Day 1 Fire Weather Outlook available here), and is thus representative of the GOES-16/17 ABI's fire detection capabilities under conditions favorable for extreme fire behavior and dangerous wildfires. Rapid detection of newly ignited wildland fire is critical in such environments because the least costly wildfires are commonly the ones that receive strong initial attack and are suppressed while still small (Pyne 2015). Both observing platforms utilized in this case study represent examples of existing in-situ and space-based technological solutions for early wildfire detection, with the possibility shown of spaceborne instruments detecting wildfires within a minute of ignition. If data from such instruments are fully assimilated and implemented into fire/emergency management operations, they could immediately support timely ignition detection, fire tracking, and the provision of warnings for public and responder safety (Berlin and Hieb 2019).

Acknowledgments: This study resulted from joint work of the National Wildfire Coordinating Group's Satellite Data Task Team and a NWS/University Corporation for Atmospheric Research training development effort to improve operational use of satellite data for wildland fire. Several authors of this paper are common members of these collaborations. Additional contributors associated with these working groups include: Billy Gardunio, Dr. Wilfrid Schroeder, Dr. Susan O’Neill, Drew Daily, Cole Belongie, Sean Triplett, Craig Thompson, Dan Borsum, Anna Schneider, Ryan Walbrun, Patrick Dills, Amy Stevermer, and Tony Mancus. In addition, the authors would like to thank Dr. Vivek Mahale, John Brost, Greg Patrick, Dr. Patrick Marsh, Greg Murdoch, Dr. Michelle Hawkins, David Andra, and Rick Smith, as well as the two anonymous reviewers. The scientific results and conclusions, as well as any view or opinions expressed herein, are those of the author(s) and do not necessarily reflect the views of NWS, NOAA, or the Department of Commerce.

\section{REFERENCES}

Berlin, G. and M. Hieb, 2019: Wildland urban interface (WUI) fire operational requirements and capability analysis. Report of Findings, U.S. Dept. Homeland Security. [Available online at https://www.dhs.gov/sites/ default/files/publications/wui fire report of findings july 24_2019v2 508.pdf] 
Cal Fire, cited 2019: Kincade Fire incident overview. [Available online at https://www.fire.ca.gov/ incidents/2019/10/23/kincade-fire/]

CIRA, 2020: Fire Temperature RGB Quick Guide. [Available online at http://rammb.cira.colostate.edu/training/visit/ quick guides/Fire Temperature RGB.pdf]

Dozier, J., 1981: A method for satellite identification of surface temperature fields of subpixel resolution. Remote Sens. Environ., 11, 221-229.

Elmer, N. J., E. Berndt, and G. J. Jedlovec, 2016: Limb correction of MODIS and VIIRS infrared channels for the improved interpretation of RGB composites. $J$. Atmos. Oceanic Technol., 33, 1073-1087.

Elsenheimer, C. B. and C. M. Gravelle, 2019: Introducing lightning threat messaging using the GOES-16 Day Cloud Phase Distinction RGB composite. Wea. Forecasting, 34, 1587-1600.

Fuell, K. K., B. J. Guyer, D. Kann, A. L. Molthan, and N. Elmer, 2016: Next generation satellite RGB dust imagery leads to operational changes at NWS Albuquerque. $J$. Oper. Meteor., 4, 75-91. [Available online at http:// nwafiles.nwas.org/jom/articles/2016/2016-JOM6/2016JOM6.pdf]

Lindley, T. T., A. R. Anderson, V. N. Mahale, T. S. Curl, W. E. Line, S. S. Lindstrom, and A. S. Bachmeier, 2016: Wildfire detection notifications for impact-based decision support services in Oklahoma using geostationary super rapid scan satellite imagery. J. Operational Meteor., 4(14), 182-191, doi: http://dx.doi.org/10.15191/ nwajom.2016.0414.

, D. L. Andra, R. D. Smith, T. S. Curl, A. B. Zwink, D. A. Speheger, R. R. Barnes, D. C. Daily, B. R. Smith, and P. G. Witsaman, 2019: Proposed implementation of warn-on-detection fire warnings for public and firefighter safety. 5 th Conf. Weather Warnings and Communications, San Diego, CA, Amer. Meteor. Soc., 4.1. [Available online at https://ams.confex.com/ams/47BC5WxComm/ meetingapp.cgi/Paper/358595]

NOAA, 2018: Wildfire season in southern Plains off to a strong start after a dry winter: fire 'hotspots' detected earlier than ever, thanks to NOAA's GOES-East. Press release, March 16, 2018. [Available online at https:// www.noaa.gov/news/wildfire-seasonin-southern-plainsoff-to-strong-start-after-dry-winter]

Pletsch, M. A. J. S., T. S. Körting, F. C. Morita, F. Morelli, O. O. Bittencourt, and P. S. S. Victorino, 2019: Using GOES-16 time series to characterize near real-time active fires in Cerrado. Proceedings, XX GEOINFO, p 66-77. Sāo José dos Campos, SP, Brazil. [Available online at https://www.researchgate.net/profile/Mikhaela Pletsch/publication/337227513 Using GOES-16 Time Series to characterize near real-time active fires in Cerrado/links/5dcc51454585156b35102222/ Using-GOES-16-Time-Series-to-characterize-near-realtime-active-fires-in-Cerrado.pdf]
Pyne, S. J., 2015: Between two fires: a fire history of contemporary America. The University of Arizona Press. Tucson, AZ.

Schmidt, C. C., 2020: Monitoring fires with the GOES-R series. In S. J. Goodman, T. J. Schmit, J. Daniels, and R. J. Redmon (Eds.), The GOES-R series: a new generation of geostationary environmental satellites, p.145-163.

Schmit, T. J., P. Griffith, M. M. Gunshor, J. M. Daniels, S. J. Goodman, and W. J. Lebair, 2017: A closer look at the ABI on the GOES-R series. Bull. Amer. Meteor. Soc., 98, 681-698.

Uccellini, L. W., J. E. Ten Hoeve, 2019: Evolving the National Weather Service to build a Weather-Ready Nation: connecting observations, forecasts, and warnings to decision-makers through impact-based decision support services. Bull. Amer. Meteor. Soc., (100), 10. 1923-1942, https://doi.org/10.1175/ BAMS-D-18-0159.1.

Weaver, J. F., J. F. W. Purdom, and T. L. Schneider, 1995: Observing forest fires with the GOES-8, 3.9- $\mu$ m imaging channel. Wea. Forecasting, 10, 803-808.

, D. Lindsey, D. Bikos, C. C. Schmidt, and E. Prins, 2004: Fire detection using GOES rapid scan imagery. Wea. Forecasting, 19, 496-510. 